\title{
Mediation of Neuronal Apoptosis by Kv2.1-Encoded Potassium Channels
}

\author{
Sumon Pal, ${ }^{1}$ Karen A. Hartnett, ${ }^{1}$ Jeanne M. Nerbonne, ${ }^{3}$ Edwin S. Levitan, ${ }^{2}$ and Elias Aizenman ${ }^{1}$ \\ Departments of ${ }^{1}$ Neurobiology and ${ }^{2}$ Pharmacology, University of Pittsburgh School of Medicine, Pittsburgh, Pennsylvania 15261, and ${ }^{3}$ Department of \\ Molecular Biology and Pharmacology, Washington University School of Medicine, St. Louis, Missouri 63110
}

\begin{abstract}
Cellular $\mathrm{K}^{+}$efflux is a requisite event in the unfolding of apoptosis programs across many types of cells and death-inducing stimuli; however, the molecular identities of the ion channels mediating this key event have remained undefined. Here, we show that Kv2.1encoded $\mathrm{K}^{+}$channels are responsible for the expression of apoptosis in cortical neurons in vitro. Transient expression of two different dominant-negative forms of this subunit in neurons completely eliminated the enhancement of $\mathrm{K}^{+}$currents that normally accompanies the cell death process. Importantly, neurons deficient in functional Kv2.1-encoded $\mathrm{K}^{+}$channels were protected from oxidant and staurosporine-induced apoptosis. Finally, Chinese hamster ovary cells, which do not express endogenous voltage-gated $\mathrm{K}^{+}$channels, became substantially more sensitive to apoptosis after transient expression of wild-type Kv2.1. These results suggest that Kv2.1-encoded $\mathrm{K}^{+}$channels are necessary for the apoptotic signaling cascade in mammalian cortical neurons in culture and are sufficient for increasing the susceptibility to apoptogens in a nonexcitable cell.
\end{abstract}

Key words: potassium channels; Kv2.1; apoptosis; neurotoxicity; cortical neurons; Chinese hamster ovary; luciferase; transfection

\section{Introduction}

Elevation of extracellular $\mathrm{K}^{+}$blocks apoptosis in a large number of cell types by preventing the cell death-inducing efflux of this ion (Hughes and Cidlowski, 1999). In neurons, apoptosis is accompanied by a p38-dependent amplification of voltage-gated $\mathrm{K}^{+}$currents that precedes caspase activation (Yu et al., 1997; McLaughlin et al., 2001) and appears to provide the exit route for this cation. Indeed, $\mathrm{K}^{+}$channel blockers such as tetraethylammonium inhibit the apoptotic process triggered by stimuli as diverse as serum deprivation, staurosporine, ischemia, amyloid $\beta$ peptide toxicity, and oxidative stress (Yu et al., 1997, 1998; Aizenman et al., 2000; Chi and Xu, 2000; McLaughlin et al., 2001). In spite of the abundance of data implicating $\mathrm{K}^{+}$channels in apoptosis, the molecular identity of the specific ion channel mediating the enhanced $\mathrm{K}^{+}$currents has remained undefined. In the present study, we identify this channel in cortical neurons in culture and thereby establish a crucial and early molecular component of neuronal apoptosis in vitro.

\section{Materials and Methods}

Cell culture and transfection procedures. Enhanced green fluorescent protein (eGFP) (pCMVIE-eGFP; Clontech, Palo Alto, CA) was used as a marker for the identification of positively transfected neurons for electrophysiology. The cDNAs for the potassium channel constructs, $\mathrm{pBK}$

Received Jan. 27, 2003; revised April 9, 2003; accepted April 9, 2003.

This work was supported by National Institutes of Health Grants NS43277 (E.A.), HL55312 (E.S.L.), HL34161 (J.M.N.), and NS30676 (J.M.N.), and by a predoctoral award from the American Heart Association (S.P.). We thankS Du and B. Gabris for technical assistance, and B. A. McLaughlin, D. Leszkiewicz, D. DeFranco, D. Levinthal, P. Land and K. Kandler for valuable discussions and suggestions.

Correspondence should be addressed to Dr. Elias Aizenman, Department of Neurobiology, University of Pittsburgh School of Medicine, E1456 Biomedical Science Tower, Pittsburgh, PA 15261. E-mail: redox@pitt.edu. Copyright $\odot 2003$ Society for Neuroscience $\quad$ 0270-6474/03/234798-05\$15.00/0
CMV Kv2.1 N216, pBK Kv2.1 W365C/Y380T, pEF6/V5-His-TOPO Kv2.2 W373C/Y388T, and peGFP-Kv1.4, were prepared as described previously (Burke et al., 1999; Xu et al., 1999; Malin and Nerbonne, 2002). The pBK CMV phagemide parent vector was purchased from Stratagene (La Jolla, CA). The mammalian expression construct for luciferase, pUHC13-3, was a gift from Dr. H. Bujard (Heidelberg, Germany) and pKv2.1 was a gift from J. Trimmer (Stony Brook, NY). Cortical cultures were prepared from embryonic day 16 rat embryos and grown on $12 \mathrm{~mm}$ glass coverslips as described previously (Hartnett et al., 1997). Cultures were transiently transfected at 25-29 d in vitro in the presence of $2 \%$ serum using Lipofectamine 2000 (Invitrogen, Carlsbad, CA) (Ohki et al., 2001). In brief, $1.5 \mu \mathrm{g}$ of cDNA was diluted in $50 \mu \mathrm{l}$ Opti-Mem I medium and combined with $50 \mu \mathrm{l}$ of Opti-Mem I medium containing $4 \mu \mathrm{l}$ of Lipofectamine 2000 reagent. Complexes were allowed to form for $30 \mathrm{~min}$ at room temperature before addition to the cortical cultures. Cells were maintained for $24-48 \mathrm{hr}$ at $37^{\circ} \mathrm{C}, 5 \% \mathrm{CO}_{2}$ before recording and toxicity assays. Chinese hamster ovary $(\mathrm{CHO})$ cells were seeded at $2.8 \times 10^{5}$ cells per well into six-well plates $24 \mathrm{hr}$ before transfection. Cells were transfected in serum-free medium with $6 \mu$ l of Lipofectamine reagent (Invitrogen) and a total of $1.4 \mu \mathrm{g}$ of DNA per well. Recordings and toxicity assays were performed $2 \mathrm{~d}$ after transfection.

Electrophysiological measurements. Recordings were conducted using the whole-cell configuration of the patch-clamp technique as described previously (McLaughlin et al., 2001) from GFP-expressing cells (Santos and Aizenman, 2002). The extracellular solution contained (in mM): 115 $\mathrm{NaCl}, 2.5 \mathrm{KCl}, 2.0 \mathrm{MgCl}$, 10 HEPES, 0.1 BAPTA, 10 D-glucose; $\mathrm{pH}$ was adjusted to $7.2 ; 0.1 \mathrm{~mm}$ tetrodotoxin was added to inhibit voltage-gated sodium channels. The intracellular (electrode) solution contained (in mM): $120 \mathrm{KCl}, 1.5 \mathrm{MgCl}_{2}, 1 \mathrm{CaCl}_{2}, 2.0 \mathrm{Na}_{2}$ ATP, 1 BAPTA, $10 \mathrm{HEPES}$, pH 7.2. Measurements were obtained under voltage clamp with an Axopatch 200 amplifier (Axon Instruments, Foster City, CA) and pClamp software (Axon Instruments) using $2 \mathrm{M} \Omega$ electrodes. Partial compensation (80\%) for series resistance was performed in all cases. Currents were filtered at 2 $\mathrm{kHz}$ and digitized at $10 \mathrm{kHz}$ (Digidata; Axon Instruments). Potassium currents were evoked with a series of incremental $80 \mathrm{msec}$ voltage steps to 
a

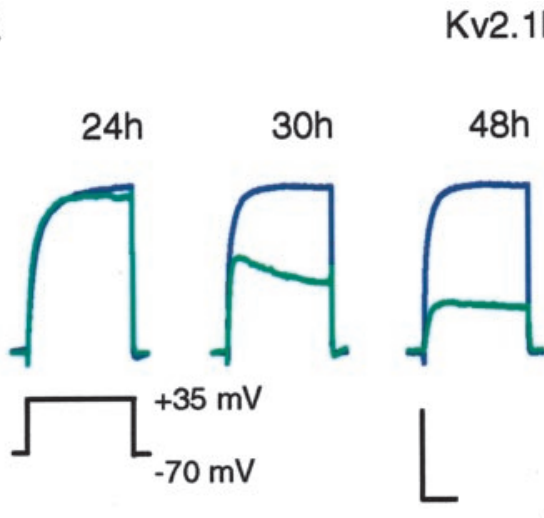

b

Kv2.1N216

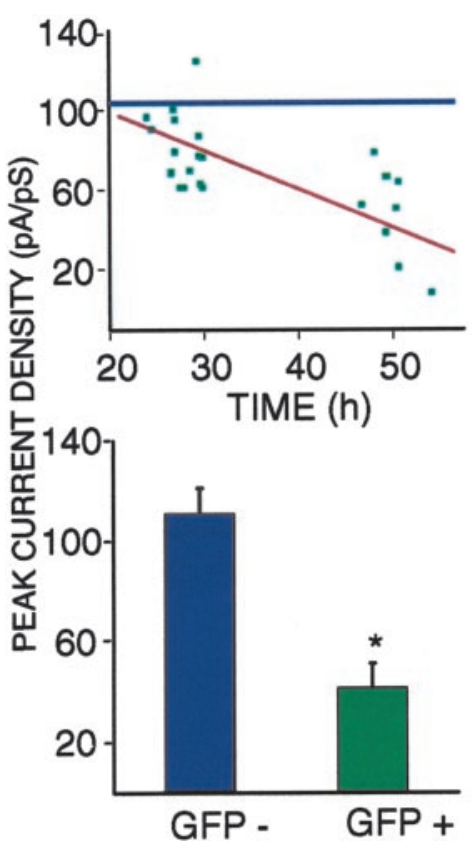

$\mathrm{nA}$

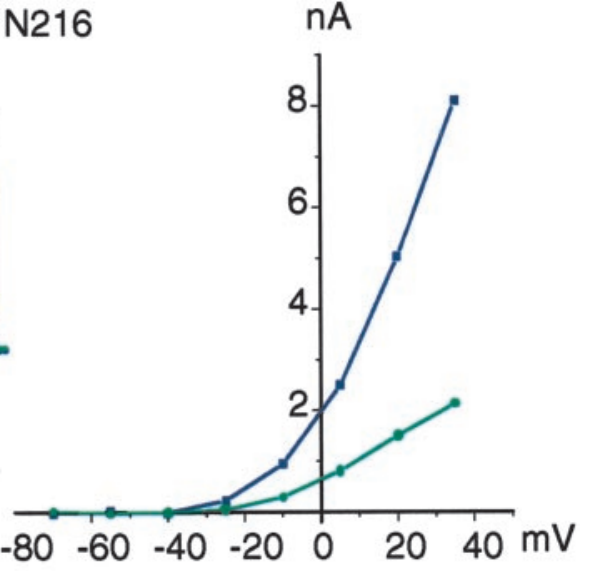

C

Kv2.1W365C/Y380T

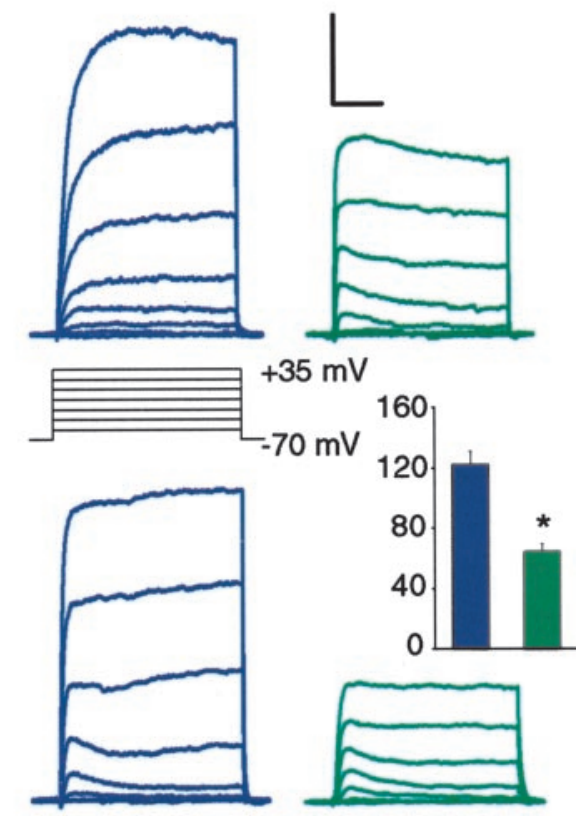

Luciferase activity as an index of cell viability (Boeckman and Aizenman, 1996; Rameau et al., 2000) was measured using the GeneLux Kit (L002-100, PerkinElmer Life Sciences, Boston, MA) in a Victor2 Multilabel Counter (PerkinElmer Life Sciences). Cell lysates were prepared, and $10 \mu \mathrm{l}$ of sample volumes were measured immediately after the addition of $100 \mu \mathrm{l}$ of each luciferin and ATP reagent. Toxicity in $\mathrm{CHO}$ cells was determined by cell counts $24 \mathrm{hr}$ after DTDP treatment. Counts were conducted by determining the number of GFP-positive cells in 10 adjacent fields using a $40 \times$ objective.

\section{Results}

Expression of dominant-negative Kv2.1 in cortical neurons in vitro

To identify the channel mediating the enhanced potassium currents associated with apoptosis (Yu et al., 1997; McLaughlin et al., 2001), we first transiently expressed a dominant-negative (DN) truncation mutant of Kv2.1 (Kv2.1N216) in cortical neuronal cultures. Expression of Kv2.1N216 has been shown previously to depress delayed rectifier $\mathrm{K}^{+}$currents in mouse ventricular myocytes (Xu et al., 1999). Whole-cell recordings from neurons transiently expressing Kv2.1N216 and eGFP revealed a $60 \%$ reduction in delayed rectifier $\mathrm{K}^{+}$current density when compared with eGFP negative, presumably untransfected neurons growing on the same coverslips (Fig. 1b). We had previously described a similar high degree of correlation (90\%) between the coexpression of transfected ion channels and eGFP in cortical neurons in vitro (Santos and Aizenman, 2002), suggesting that plasmids transfected together generally express together in this system. The reduction in $\mathrm{K}^{+}$ currents in Kv2.1N216-transfected cells occurred in a time-dependent manner, not evident at $24 \mathrm{hr}$ after transfection but becoming very prominent by $48 \mathrm{hr}$ (Fig. $1 a, b)$. In addition to the truncation mutant, we also used a DN form of Kv2.1 that contains two mutations in the pore region of the channel (Kv2.1W365C/Y380T) (Malin and Nerbonne, 2002). Forty-eight hours after cotransfection of this construct and eGFP, substantial reductions (50\%) in delayed rectifier $\mathrm{K}^{+}$current densities were also evident in eGFP-positive but not eGFP-negative

$35 \mathrm{mV}$ from a holding potential of $-70 \mathrm{mV}$. Steady-state current amplitudes were measured relative to baseline $80 \mathrm{msec}$ after the initiation of each voltage step and normalized to cell capacitance.

Toxicity assays. Neuronal toxicity assays were conducted at 24 and 48 hr after transfection in parallel with electrophysiological recordings but in luciferase cotransfected cells. Cells were rinsed immediately before drug treatment with Minimal Essential Medium with Earle's salts (without phenol red) containing $0.01 \%$ bovine serum albumin and $25 \mathrm{~mm}$ HEPES. Cells were exposed to either DMSO vehicle $(0.1 \%)$ or $100 \mu \mathrm{M}$ 2,2' -dithiodipyridine (DTDP) for $10 \mathrm{~min}$ at $37^{\circ} \mathrm{C}, 5 \% \mathrm{CO}_{2}$. Staurosporine $(0.5 \mu \mathrm{M})$ and NMDA $(200 \mu \mathrm{M})$ exposures occurred overnight $(24 \mathrm{hr})$. cells on the same coverslips (Fig. 1c). Therefore, similar to what has been proposed for hippocampal (Murakoshi and Trimmer, 1999) and sympathetic (Malin and Nerbonne, 2002) neurons, Kv2.1encoded channels seem to mediate a significant portion of the delayed rectifier current in rat cortical neurons in tissue culture.

\section{Kv2.1-encoded channels mediate the current enhancement} during apoptosis

We subsequently investigated the effect of Kv2.1 DN expression on apoptosis-associated increases in voltage-gated $\mathrm{K}^{+}$currents. 
Forty-eight hours after transfection with Kv2.1N216 and eGFP, cells were treated for $10 \mathrm{~min}$ with $100 \mu \mathrm{M}$ DTDP, a cell-permeant oxidant previously shown to induce an apoptotic cascade characterized by pronounced enhancements in $\mathrm{K}^{+}$currents after the liberation of intracellular zinc and phosphorylation of the mitogen-activated protein kinase p38 (McLaughlin et al., 2001). Outward $\mathrm{K}^{+}$currents in eGFP-positive and eGFP-negative cells on the same coverslips were examined $\sim 4 \mathrm{hr}$ after DTDP treatment. Consistent with previous findings (McLaughlin et al., 2001), untransfected (eGFP negative) neurons showed a robust increase in outward $\mathrm{K}^{+}$currents after exposure to DTDP, often becoming too large at high-voltage steps to adequately maintain under voltage clamp (Fig. $2 a$ ). In contrast, neurons transfected with the Kv2.1 DN vector had drastically smaller current densities after DTDP treatment (Fig. 2a). A lack of apoptosis-related increase in $\mathrm{K}^{+}$current density was also seen after introduction of the pore mutant Kv2.1W365C/Y380T in cells exposed to DTDP (Fig. 2b). Moreover, current densities from DTDP-treated neurons transfected with either Kv2.1 DN construct were not significantly different from vehicle-treated, DN-transfected cells (Fig. $2 a, b)$, suggesting that the $\mathrm{DN}$-induced reduction in current density after exposure to DTDP was not caused simply by an overall reduction of functioning $\mathrm{K}^{+}$channels. Indeed, the expression of a dominant-negative form of the closely related Kv2.2 $\alpha$ subunit (Kv2.2W373C/Y388T) (Malin and Nerbonne, 2002) had no effect on the increases in current density after DTDP treatment (data not shown, but see Fig. 3c); cells transfected with blank vector ( $\mathrm{pBK}$ CMV) behaved similarly to controls. Taken together these results indicate that $\mathrm{Kv} 2.1$-encoded $\mathrm{K}^{+}$channels are responsible for the increases in $\mathrm{K}^{+}$current density that occur during the apoptotic process. These data also strongly suggest that Kv2.1 and Kv2.2 do not coassemble in neurons, which although different from what has been described previously in the oocyte expression system (Blaine and Ribera, 1998), is consistent with recent findings in rat sympathetic neurons (Malin and Nerbonne, 2002).

\section{Dominant-negative Kv2.1 is neuroprotective}

On the basis of the above results, we hypothesized that neurons lacking functional Kv2.1-encoded channels might be resistant to apoptosis. To test this hypothesis, we examined the extent of DTDP or staurosporine-induced cell death in neurons transfected with the DN Kv2.1 constructs. Because the electrophysiological effects of the Kv2.1 DN constructs were observed $48 \mathrm{hr}$ but not at $24 \mathrm{hr}$ after transfection (Fig. 1), we induced apoptosis at both of these time points to ensure that any protective effects of the DN Kv2.1 constructs correlated well with their expression. Cell viability was assessed with a luciferase expression assay in cells cotransfected with the expression vector for this marker protein (Boeckman and Aizenman, 1996; Rameau et al., 2000). These experiments revealed that Kv2.1N216-transfected cells were vulnerable to both DTDP (100 $\mu \mathrm{M} ; 10 \mathrm{~min})$ and NMDA toxicity (200 $\mu \mathrm{M} ; 18 \mathrm{hr}) 24 \mathrm{hr}$ after transfection, a time point at which the effects of the Kv2.1 DN were not detected electrophysiologically (Fig. 1a). In contrast, $48 \mathrm{hr}$ after transfection, neurons were highly resistant to DTDP toxicity while still remaining susceptible to excitotoxicity (Fig. 3a). The NMDA receptor blocker MK801 (10 $\mu \mathrm{M})$ was used to inhibit excitotoxicity to ensure that the luciferase expression assay was accurately reflecting cell viability (Fig. $3 a$, inset). Expression of the parent vector (pBK) had no effect on DTDP or NMDA toxicity at either 24 or $48 \mathrm{hr}$ after transfection (data not shown). Neurons transfected with Kv2.1W365/Y380T (Fig. 3b), but not those expressing the Kv2.2W373/Y388T pore mutant (Fig. 3c), were also resistant to
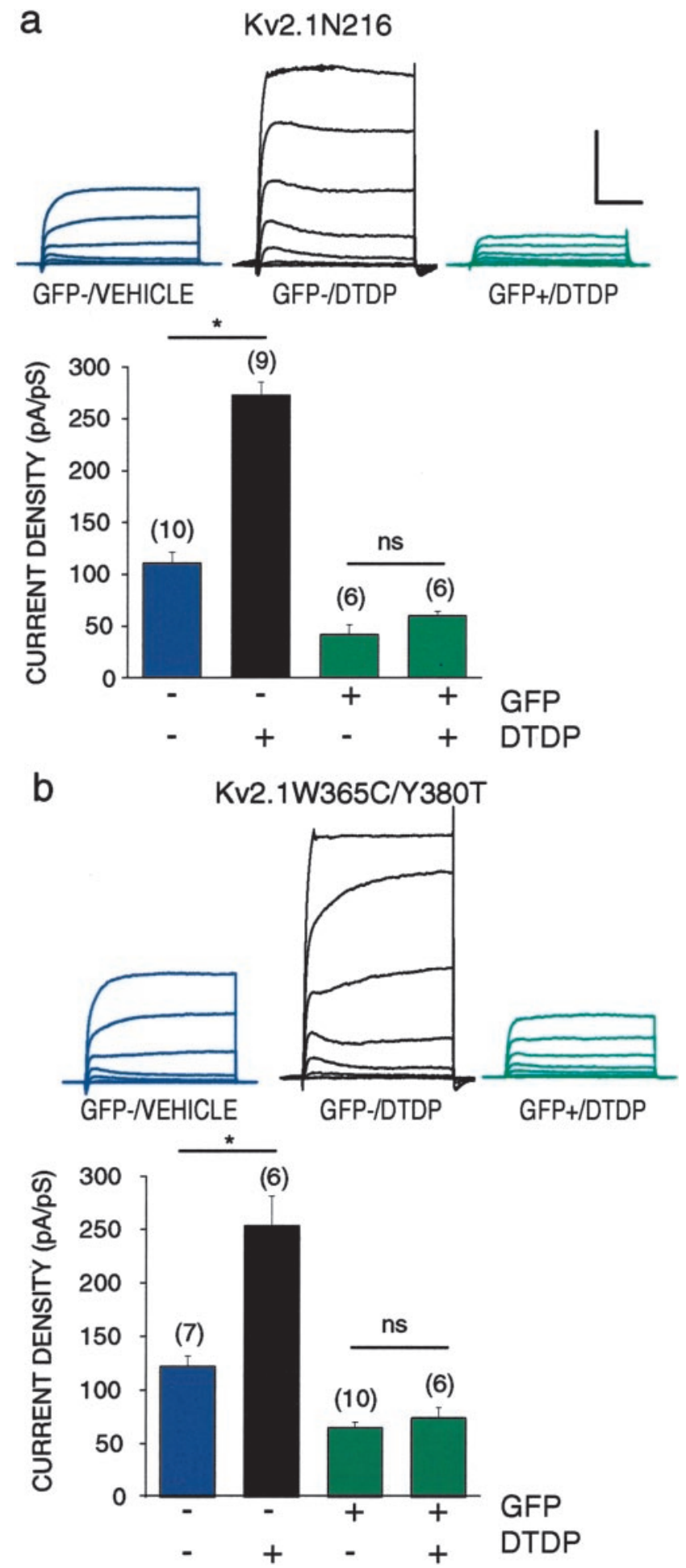

Figure 2. Kv2.1 DN expression blocks apoptosis-related enhancement of $\mathrm{K}^{+}$currents. $a$, Top, Whole-cell currents evoked by a single voltage step from -70 to $5 \mathrm{mV}$ from GFP-negative (blue) and GFP-positive (green) neurons in cultures transfected with Kv2.1N216 $4 \mathrm{hr}$ after treatment with either vehicle or $100 \mu \mathrm{m}$ DTDP (10 min). Bottom, Mean \pm SEM current densities from GFP-negative and GFP-positive cells obtained $4 \mathrm{hr}$ after treatment with vehicle $(0.001 \%$ DMSO) or DTDP. Calibration: $7 \mathrm{nA}, 20 \mathrm{msec}\left({ }^{*} p<0.001\right.$; ANOVA, Bonferoni). B, Results from identical experiment using the Kv2.1 pore mutant $\left({ }^{*} p<0.001\right)$.

staurosporine ( $0.5 \mu \mathrm{M} ; 24 \mathrm{hr}) 48 \mathrm{hr}$ after transfection. These results demonstrate the need for functional Kv2.1-encoded channels in the cell death pathways induced by two distinct apoptogenic stimuli. 
a

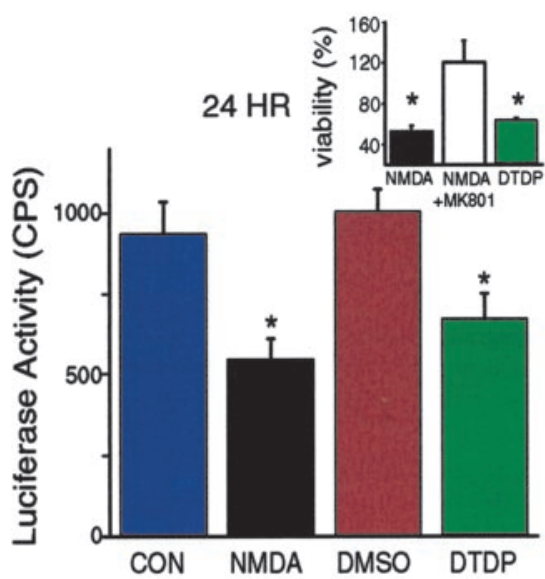

Kv2.1N216

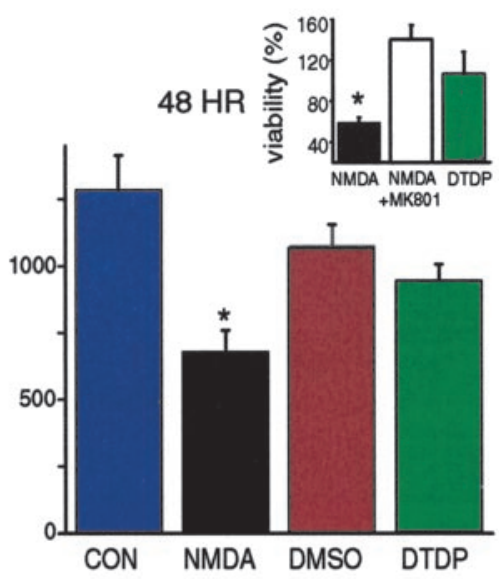

Enhancement of apoptosis in Kv2.1expressing $\mathrm{CHO}$ cells

Finally, we sought to establish whether expression of Kv2.1 in cells normally lacking Kv2.1-encoded $\mathrm{K}^{+}$channels would increase their sensitivity to an injurious stimulus. $\mathrm{CHO}$ cells, which do not express any endogenous voltage-gated $\mathrm{K}^{+}$channels (Yu and Kerchner, 1998), were transfected with wild-type Kv2.1, and the effects of DTDP were examined. CHO cells transiently expressing Kv2.1 and eGFP were exposed to DTDP for $5 \mathrm{~min}$ at a concentration $(5 \mu \mathrm{M})$ that did not alter the viability of cells transfected with eGFP and an unrelated, mock vector (the NMDA receptor subunit NR1a). These experiments revealed that the introduction of Kv2.1 induced a pronounced increase in sensitivity to DTDP (Fig. 3d). In contrast, $\mathrm{CHO}$ cells expressing an eGFP-Kv1.4 fusion construct (Burke et al., 1999) did not show an appreciable enhanced sensitivity to DTDP (Fig. $3 c$ ), although the $\mathrm{K}^{+}$currents that were expressed (which lack $\mathrm{N}$-terminal inactivation) (Burke et al., 1999) resemble Kv2.1-encoded $\mathrm{K}^{+}$currents (Fig. $3 c$, inset). DTDP-induced cell death in Kv2.1-expressing CHO cells was blocked by the broad-spectrum caspase inhibitor butoxy-carbonyl-aspartatefluoromethyl ketone (BAF) $(50 \mu \mathrm{M})$, indicating that the $\mathrm{CHO}$ cells expressing Kv2.1 were more susceptible to apoptotic cell death (Fig. 3c). We were unable to determine whether $\mathrm{K}^{+}$currents in $\mathrm{CHO}$ cells expressing Kv2.1 were enhanced in a manner similar to neuronal currents after exposure to apoptogens. This was because $\mathrm{K}^{+}$current amplitudes in untreated, transfected $\mathrm{CHO}$ cells showed an extremely high degree of variability, even among cells in the same coverslip. Nonetheless, these results strongly suggest that Kv2.1-encoded $\mathrm{K}^{+}$channels have a unique interaction with cell death pathways, even in cells that do not normally express these channels.

In light of the results with $\mathrm{CHO}$ cells, we cotransfected neurons with eGFPKv1.4 and Kv2.1W365/Y380T to determine whether expression of an exogenous delayed rectifier could substitute for Kv2.1 in mediating the $\mathrm{K}^{+}$current enhancement during apoptosis. We found that eGFP-Kv1.4 expressed extremely well in neurons and proved to be highly lethal in and of itself, similar to what has been reported after overexpression of the weakly rectifying kidney Kir1.1-encoded potassium channel in cultured hippocampal neurons (Nadeau et al., 2000). As such, it remains possible that other $\mathrm{K}^{+}$ 
channels can be involved in apoptosis, although in our preparation Kv2.1 endogenously mediates this process.

\section{Discussion}

Increased $\mathrm{K}^{+}$efflux during apoptosis and the concomitant decrease in the concentration of this cation in the cytoplasm seem to promote key events in the cell death process in a number of systems (Hughes and Cidlowski, 1999). Indeed, studies have shown that intracellular $\mathrm{K}^{+}$concentrations can decrease to levels below $50 \mathrm{~mm}$ in cells undergoing apoptotic cell death and that this change in cytoplasmic $\mathrm{K}^{+}$has a direct influence on the activity of several apoptosis-related enzymes (Barbiero et al., 1995; Hughes et al., 1997). For example, proteolytic cleavage of procaspase- 3 and endonuclease activity are not only facilitated by low $\mathrm{K}^{+}$concentrations but can be inhibited by physiological levels of this cation (Hughes et al., 1997). In addition, isolated nuclei exposed to supernatants of mitochondria that have undergone permeability transition exhibit DNA fragmentation only at low $\mathrm{K}^{+}$concentrations (Dallaporta et al., 1998). Finally, $\mathrm{Ca}^{2+}$ induced cytochrome $c$ release from isolated rat brain mitochondria seems to occur only in low levels of $\mathrm{K}^{+}$in the assay medium (Brustovetsky et al., 2002).

Previous studies have suggested, but not proven, that $\mathrm{K}^{+}$efflux in non-neuronal models of apoptosis can occur through either the two-pore domain-containing $\mathrm{K}^{+}$channel (Trimarchi et al., 2002) or via a $\mathrm{K}^{+} \mathrm{Cl}^{-}$cotransporter (Kim et al., 2001). The results presented here, however, clearly demonstrate that Kv2.1encoded $\mathrm{K}^{+}$channels may provide the primary exit route for $\mathrm{K}^{+}$ in neurons undergoing apoptotic cell death. In addition, expression of Kv2.1 in cells that do not normally express any $\mathrm{K}^{+}$channels is sufficient to enhance sensitivity to a sublethal concentration of an apoptotic stimulus. This result suggests that it may be useful to target functional Kv2.1 expression to tumor cells that have become resistant to chemotherapeutic agents. Our data also suggest that Kv2.1-encoded potassium channels may be important and novel therapeutic targets against a host of neurological conditions where apoptosis has been implicated.

\section{References}

Aizenman E, Stout AK, Hartnett KA, Dineley KE, McLaughlin B, Reynolds IJ (2000) Induction of neuronal apoptosis by thiol oxidation: putative role of intracellular zinc release. J Neurochem 75:1878-1888.

Barbiero G, Duranti F, Bonelli G, Amenta JS, Baccino FM (1995) Intracellular ionic variations in the apoptotic death of $\mathrm{L}$ cells by inhibitors of cell cycle progression. Exp Cell Res 217:410-418.

Blaine JT, Ribera AB (1998) Heteromultimeric potassium channels formed by members of the Kv2 subfamily. J Neurosci 18:9585-9593.

Boeckman FA, Aizenman E (1996) Pharmacological properties of acquired excitotoxicity in Chinese hamster ovary cells transfected with $\mathrm{N}$-methylD-aspartate receptor subunits. J Pharmacol Exp Ther 279:515-523.

Brustovetsky N, Brustovetsky T, Jemmerson R, Dubinsky JM (2002) Calcium-induced cytochrome $\mathrm{c}$ release from CNS mitochondria is associated with the permeability transition and rupture of the outer membrane. Neurochemistry 80:207-218.
Burke NA, Takimoto K, Li D, Han W, Watkins SC, Levitan ES (1999) Distinct structural requirements for clustering and immobilization of $\mathrm{K}+$ channels by PSD-95. J Gen Physiol 113:71-80.

Chi XX, Xu ZC (2000) Differential changes of potassium currents in CA1 pyramidal neurons after transient forebrain ischemia. J Neurophysiol 84:2834-2843.

Dallaporta B, Hirsch T, Susin SA, Zamzami N, Larochette N, Brenner C, Marzo I, Kroemer G (1998) Potassium leakage during the apoptotic degradation phase. J Immunol 160:5605-5615.

Hartnett KA, Stout AK, Rajdev S, Rosenberg PA, Reynolds IJ, Aizenman E (1997) NMDA receptor-mediated neurotoxicity: a paradoxical requirement for extracellular $\mathrm{Mg}^{2+}$ in $\mathrm{Na}+/ \mathrm{Ca}^{2+}$-free solutions in rat cortical neurons in vitro. J Neurochem 68:1836-1845.

Hughes Jr FM, Cidlowski JA (1999) Potassium is a critical regulator of apoptotic enzymes in vitro and in vivo. Adv Enzyme Regul 39:157-171.

Hughes Jr FM, Bortner CD, Purdy GD, Cidlowski JA (1997) Intracellular $\mathrm{K}+$ suppresses the activation of apoptosis in lymphocytes. J Biol Chem 272:30567-30576.

Kim JA, Kang YS, Lee YS (2001) Involvement of $\mathrm{K}(+)-\mathrm{Cl}(-)$-cotransport in the apoptosis induced by $N$-ethylmaleimide in HepG2 human hepatoblastoma cells. Eur J Pharmacol 418:1-5.

Malin SA, Nerbonne JM (2002) Delayed rectifier $\mathrm{K}^{+}$currents, $I_{\mathrm{K}}$, are encoded by Kv $2 \alpha$-subunits and regulate tonic firing in mammalian sympathetic neurons. J Neurosci 22:10094-10105.

McLaughlin BA, Pal S, Tran MP, Parsons AA, Barone FC, Erhardt JA, Aizenman E (2001) p38 activation is required upstream of potassium current enhancement and caspase cleavage in thiol oxidant-induced neuronal apoptosis. J Neurosci 21:3303-3311.

Murakoshi H, Trimmer JS (1999) Identification of the Kv2.1 $\mathrm{K}^{+}$channel as a major component of the delayed rectifier $\mathrm{K}^{+}$current in rat hippocampal neurons. J Neurosci 19:1728-1735.

Nadeau H, McKinney S, Anderson DJ, Lester HA (2000) ROMK1 (Kir1.1) causes apoptosis and chronic silencing of hippocampal neurons. J Neurophysiol 84:1062-1075.

Ohki EC, Tilkins ML, Ciccarone VC, Price PJ (2001) Improving the transfection efficiency of post-mitotic neurons. J Neurosci Methods 112:95-99.

Rameau GA, Akaneya Y, Chiu L, Ziff EB (2000) Role of NMDA receptor functional domains in excitatory cell death. Neuropharmacology 39:2255-2266.

Santos S, Aizenman E (2002) Functional expression of muscle-type nicotinic acetylcholine receptors in rat forebrain neurons in vitro. Methods Find Exp Clin Pharmacol 24:63-66.

Trimarchi JR, Liu L, Smith PJ, Keefe DL (2002) Apoptosis recruits two-pore domain potassium channels used for homeostatic volume regulation. Am J Physiol Cell Physiol 282:C588-C594.

Xu H, Barry DM, Li H, Brunet S, Guo W, Nerbonne JM (1999) Attenuation of the slow component of delayed rectification, action potential prolongation, and triggered activity in mice expressing a dominant-negative Kv2 alpha subunit. Circ Res 85:623-633.

Yu SP, Kerchner GA (1998) Endogenous voltage-gated potassium channels in human embryonic kidney (HEK293) cells. J Neurosci Res 52:612-617.

Yu SP, Yeh CH, Sensi SL, Gwag BJ, Canzoniero LM, Farhangrazi ZS, Ying HS, Tian M, Dugan LL, Choi DW (1997) Mediation of neuronal apoptosis by enhancement of outward potassium current. Science 278:114-117.

Yu SP, Farhangrazi ZS, Ying HS, Yeh CH, Choi DW (1998) Enhancement of outward potassium current may participate in beta-amyloid peptideinduced cortical neuronal death. Neurobiol Dis 5:81-88. 